\title{
Reckoning Examination for Precip Soothsaying
}

\author{
D.Jeyapriya, S.Amudha, G.Michael, B.Sundarraj
}

\begin{abstract}
Rainfall is important for food production plan, water resource management. India is an agricultural country and its economy [1],[3],[5]is largely based upon productivity. Thus rainfall prediction becomes a significant factor in agricultural countries like India. On the growing importance of Rainfall studies in the climate change scenario and High Performance Computing, different Users starting from a farmer to a scientist to a policy maker needs the rainfall prediction well in advance for their application like crop planning, water storage etc. Data discovery from temporal, spatial and spatio- temporal data is critical for rainfall analysis. However, recent growth in observations and model outputs, combined with the increased availability of geographical data, presents new opportunities for the users to implement new techniques such as predictive analytics for developing a predictor which can be used for multi-scale forecasting of rainfall that is from 24 hour forecast to long-range forecast say 2-3 month in advance forecast. Hence we developed predictive analytics system for the efficient and real time prediction of rainfall over India. [2 ],[ 4],[6]
\end{abstract}

Index Terms: Agriculture, Ensemble forecasting, Rainfall Forecasting, Prediction

\section{INTRODUCTION}

Horticulture is the overwhelming occupation in India, representing around $52 \%$ of business. Since, India is an agrarian nation and its economy is to a great extent in light of harvest efficiency. [7],[ 9] ,[11]The event of delayed dry period or overwhelming precipitation at the basic phases of the harvest development and improvement may prompt huge diminish edit yield. Precipitation is critical for sustenance generation design, water asset administration and all action designs in the nature. Along these lines precipitation forecast turns into a critical factor in rural nations like India. Precipitation anticipating has been a standout amongst the most experimentally and mechanically difficult issues far and wide in the most recent century. The precipitation information is accessible for the information mining procedures which can be valuable for foreseeing the precipitation which can exceptionally helpful for taking choices over harvest planting in the zones. [8],[10] ,[12]

Revised Manuscript Received on July 22, 2019.

D.Jeyapriya,, Department of Computer Science and Engineering, Bharath Institute of Higher education and research, Chennai, India

S.Amudha ,Department of CSE,,Bharath Institute of Higher Education and Research,Chennai,Thamilnadu,India.

G.Michael, Depaetment of CSE, Bharath Institute of Higher Education and Research ,Chennai, ThamilNadu, India.

B.Sundarraj ,Department of CSE,,Bharath Institute of Higher Education and Research,Chennai,Thamilnadu,India.
The Irrigation offices are lacking, as uncovered by the way that exclusive $52.6 \%$ of the land was watered in 2009- 10 which result in agriculturists as yet being subject to precipitation, particularly the Monsoon season. A decent rainstorm brings about a powerful development for the economy in general, while a poor storm prompts a drowsy development. In the present investigation a structure for precipitation expectation from past information and present climate condition is created utilizing the prescient examination in a High Performance Computing

condition where a few programming resembles MATLAB, STATISTICA and so forth are interfaced with the protest arranged dialect to build up a multi-scale determining stage for precipitation expectation..

\section{RELATED WORK}

There have been many endeavors to figure precipitation. Precipitation estimating can apply to many time skylines, for example, here and now, medium term, and long haul periods.

A few creators plan frameworks which can figure yearly information, some attempt to gauge month to month information while some endeavor to estimate every day information. [13], [15], [ 17]

N. Sen. has exhibited long-run summer rainstorm precipitation conjecture demonstrate in view of energy relapse strategy with the utilization of Ei Nino, Eurasian snow cover, north west Europe temperature, Europe weight angle Wind design, Arabian ocean SST, east Asia weight and south Indian sea temperature in earlier year. The trial comes about demonstrated that the model mistake was 4\%. [14], [ 16], [18]

S. Nkrintra, depicted the advancement of a measurable anticipating technique for SMR over Thailand utilizing different straight relapse and nearby polynomial-based nonparametric methodologies. SST, ocean level weight (SLP), wind speed, EiNino Southern Oscillation Index (ENSO), IOD was picked as indicators. The tests demonstrated that the relationship amongst's watched and gauge precipitation. [19],[21],[23]

T. Sohn, has built up an expectation show for the event of substantial rain in South Korea utilizing various direct and coordinations relapse, choice tree and simulated neural system. [20],[22], [24]

M. T. Mebrhatu displayed for expectation classifications of precipitation (beneath, above, 


\section{Reckoning examination for precip soothsaying}

ordinary) in the good countries of Eritrea. The most powerful indicator of precipitation sum was the southern Indian Ocean SST. Test comes about demonstrated that the hit rate for the model was $70 \%$.

H. Hasani proposed human tallness expectation demonstrate in light of different polynomial relapse that was utilized effectively to estimate the development possibilities of stature with accuracy and was useful $\mathrm{i}$

n kids development examine.

Vaccari displayed plant movement time arrangement and Nutrient recuperation information for cutting edge life bolster utilizing multi variable polynomial relapse. [25],[27],[29]

In any case, in these investigations the approach is exceptionally basic as the informational collection is little, To deal with information mining in a Big information condition as all the atmosphere information are of huge size[26],[28],[30]

\section{STREAM OF THE PREDICTIVE MODEL}

Stage 1: Adopting unsupervised information characterization

system, for example, K-implies grouping method, for bunching of the watched multi-site precipitation information so as to recognize the precipitation states display in the precipitation information. [31],[33],[35]

Stage 2: Perform Principal Component Analysis (PCA) to decrease the measurements of the institutionalized indicator information, i.e. CMMACS atmosphere informational index. The dimensionally-diminished atmosphere factors speak to a vast division of the fluctuation contained in the first information. [32],[34],[36]

Stage 3: Training the Predictive model(s) to build up connection between the information containing current day institutionalized and dimensionally-diminished atmosphere indicators alongside past day(s) precipitation state and the yield information containing the present day precipitation state.

Stage 4: Applying inclination amendment for the GCM yield information to acquire predisposition rectified GCM information. [37],[39],[41]

Stage 5: Obtain central parts of GCM information by performing PCA of the inclination amended GCM information with the assistance of primary bearings got amid PCA of CMMACS atmosphere information.Stage 6: Using the prepared Predictive model to infer give day precipitation express the assistance of Principal segments acquired from GCM yield and precipitation condition of the earlier day. [38],[40]

\section{A. Plan of Multi-Scale Predictive Analytics}

Short Range Prediction(1-6hrs)

Presently throwing utilizing constant satellite information.

eg. IPL coordinate, occasion association, shutting school and so forth.

Medium Range Prediction(3-5days)

Typhoon or overwhelming precipitation utilizing meso-scale display (WRF)

$+\mathrm{PA}$ calculation

Eg. Catastrophe readiness, Warning for Fisherman,

Shutting school.

Long Range Prediction(3-6months)

Storm rain anticipating in April for JJAS utilizing GCM

Display + PA calculation

Eg. Horticulture arranging, Water administration, sustenance security and so on

Stage 6: Using the prepared Predictive model to infer give day precipitation express the assistance of Principal segments acquired from GCM yield and precipitation condition of the earlie

\section{EXECUTION AND RESULTS}

The modules are

1. Storm demonstrate (long range)

2. climate inquire about conjecture model(Short-extend) 3 . Violent wind show (precipitation day twister)

With a specific end goal to figure the abnormality of precipitation we utilize the accompanying recipe.

1 Rain(lat,lon, yr)

Volume 4, Issue 29 Published by, www.ijert.org 77

Rain (lat,lon $)=50 \mathrm{yr}=1$

For year if inconsistency (- 10 to10): Normal Year (ex 1998)

Inconsistency

On the off chance that abnormality not exactly (- 10): Drought or Deficit Year (ex 2002)

On the off chance that abnormality more than $(+10)$ : Flood or Excess Year (ex 1961).

Relapse

Relapse is a factual exact method that uses the connection between at least two quantitative factors on observational database with the goal that a result variable can be anticipated from the others.

Relapse utilize two strategies Simple straight relapse and different direct relapse models. Relapse delivers a polynomial depicting the connection between any arrangement of data sources and relating yield. Here we have considered past information to build up a relapse condition, A straight relapse condition to foresee rainstorm precipitation

\section{REFERENCES}

[1] Kumarave A., Rangarajan K.,Algorithm for automaton specification for exploring dynamic labyrinths, Indian Journal of Science and Technology,V-6,I-SUPPL5,PP-4554-4559,Y-2013

[2] P. Kavitha, S. Prabakaran "A Novel Hybrid Segmentation Method with Particle Swarm Optimization and Fuzzy C-Mean Based On Partitioning the Image for Detecting Lung Cancer" International Journal of Engineering and Advanced Technology (IJEAT) ISSN: 2249-8958, Volume-8 Issue-5, June 2019

[3] Kumaravel A., Meetei O.N.,An application of non-uniform cellula automata for efficient cryptography,2013 IEEE Conference on Information 
and Communication

Technologies,

ICT

2013,V-,I-,PP-1200-1205,Y-2013

[4] Kumarave A., Rangarajan K.,Routing alogrithm over semi-regular tessellations,2013 IEEE Conference on Information and Communication Technologies, ICT 2013,V-,I-,PP-1180-1184,Y-2013

[5]P. Kavitha, S. Prabakaran "Designing a Feature Vector for Statistical Texture Analysis of Brain Tumor" International Journal of Engineering and Advanced Technology (IJEAT) ISSN: 2249-8958, Volume-8 Issue-5, June 2019

[6]Dutta P., Kumaravel A.,A novel approach to trust based identification of leaders in social networks,Indian Journal of Science and Technology,V-9,I-10,PP--,Y-2016

[7] Kumaravel A., Dutta P.,Application of Pca for context selection for collaborative filtering,Middle - East Journal of Scientific Research,V-20,I-1,PP-88-93,Y-2014

[8] Kumaravel A., Rangarajan K.,Constructing an automaton for exploring dynamic labyrinths,2012 International Conference on Radar, Communication and Computing, ICRCC 2012,V-,I-,PP-161-165,Y-2012

[9] P. Kavitha, S. Prabakaran "Adaptive Bilateral Filter for Multi-Resolution in Brain Tumor Recognition" International Journal of Innovative Technology and Exploring Engineering (IJITEE) ISSN: 2278-3075, Volume-8 Issue-8 June, 2019

[10] Kumaravel A.,Comparison of two multi-classification approaches for detecting network attacks, World Applied Sciences Journal,V-27,I-11,PP-1461-1465,Y-2013

[11] Tariq J., Kumaravel A.,Construction of cellular automata over hexagonal and triangular tessellations for path planning of multi-robots,2016 IEEE International Conference on Computational Intelligence and Computing Research, ICCIC 2016,V-,I-,PP--,Y-2017

[12] Sudha M., Kumaravel A.,Analysis and measurement of wave guides using poisson method,Indonesian Journal of Electrical Engineering and Computer Science,V-8,I-2,PP-546-548,Y-2017

[13] Ayyappan G., Nalini C., Kumaravel A.,Various approaches of knowledge transfer in academic social network,International Journal of Engineering and Technology,V-,I-,PP-2791-2794,Y-2017

[14] Kaliyamurthie, K.P., Sivaraman, K., Ramesh, S. Imposing patient data privacy in wireless medical sensor networks through homomorphic cryptosystems 2016, Journal of Chemical and Pharmaceutical Sciences 92.

[15] Kaliyamurthie, K.P., Balasubramanian, P.C. An approach to multi secure to historical malformed documents using integer ripple transfiguration 2016 Journal of Chemical and Pharmaceutical Sciences 92 .

[16] A.Sangeetha,C.Nalini,"Semantic Ranking based on keywords extractions in the web", International Journal of Engineering \& Technology, 7 (2.6) (2018) 290-292

[17] S.V.GayathiriDevi,C.Nalini,N.Kumar,"An efficient software verification using multi-layered software verification tool "International Journal of Engineering \& Technology, 7(2.21)2018 454-457

[18] C.Nalini,ShwtambariKharabe,"A Comparative Study On Different Techniques Used For Finger - Vein Authentication", International Journal Of Pure And Applied Mathematics, Volume 116 No. 8 2017, 327-333, Issn: 1314-3395

[19] M.S. Vivekanandan and Dr. C. Rajabhushanam, "Enabling Privacy Protection and Content Assurance in Geo-Social Networks", International Journal of Innovative Research in Management, Engineering and Technology, Vol 3, Issue 4, pp. 49-55, April 2018.

[20] Dr. C. Rajabhushanam, V. Karthik, and G. Vivek, "Elasticity in Cloud Computing", International Journal of Innovative Research in Management, Engineering and Technology, Vol 3, Issue 4, pp. 104-111, April 2018.

[21] K. Rangaswamy and Dr. C. Rajabhushanamc, "CCN-Based Congestion Control Mechanism In Dynamic Networks", International Journal of Innovative Research in Management, Engineering and Technology, Vol 3, Issue 4, pp. 117-119, April 2018.

[22] Kavitha, R., Nedunchelian, R., "Domain-specific Search engine optimization using healthcare ontology and a neural network backpropagation approach", 2017, Research Journal of Biotechnology, Special Issue 2:157-166

[23] Kavitha, G., Kavitha, R., "An analysis to improve throughput of high-power hubs in mobile ad hoc network" , 2016, Journal of Chemical and Pharmaceutical Sciences, Vol-9, Issue-2: 361-363

[24] Kavitha, G., Kavitha, R., "Dipping interference to supplement throughput in MANET" , 2016, Journal of Chemical and Pharmaceutical Sciences, Vol-9, Issue-2: 357-360
[25] Michael, G., Chandrasekar, A.,'Leader election based malicious detection and response system in MANET using mechanism design approach", Journal of Chemical and Pharmaceutical Sciences(JCPS) Volume 9 Issue 2, April - June 2016

[26] Michael, G., Chandrasekar, A.,"Modeling of detection of camouflaging worm using epidemic dynamic model and power spectral density", Journal of Chemical and Pharmaceutical Sciences(JCPS) Volume 9 Issue 2, April - June 2016.

[27] Pothumani, S., Sriram, M., Sridhar, J., Arul Selvan, G., Secure mobile agents communication on intranet,Journal of Chemical and Pharmaceutical Sciences, volume 9, Issue 3, Pg No S32-S35, 2016

[28] Pothumani, S., Sriram, M., Sridhar, Various schemes for database encryption-a survey, Journal of Chemical and Pharmaceutical Sciences, volume 9, Issue 3, Pg NoS103-S106, 2016

[29] Pothumani, S., Sriram, M., Sridhar, A novel economic framework for cloud and grid computing, Journal of Chemical and Pharmaceutical Sciences, volume 9, Issue 3, Pg No S29-S31, 2016

[30] Priya, N., Sridhar, J., Sriram, M. "Ecommerce Transaction Security Challenges and Prevention Methods- New Approach" 2016 ,Journal of Chemical and Pharmaceutical Sciences, JCPS Volume 9 Issue 3.page no:S66-S68

[31] Priya, N.,Sridhar,J.,Sriram, M."Vehicular cloud computing security issues and solutions" Journal of Chemical and Pharmaceutical Sciences(JCPS) Volume 9 Issue 2, April - June 2016

[32] Priya, N., Sridhar, J., Sriram, M. "Mobile large data storage security in cloud computing environment-a new approach" JCPS Volume 9 Issue 2. April - June 2016

[33] Anuradha.C, Khanna.V, "Improving network performance and security in WSN using decentralized hypothesis testing "Journal of Chemical and Pharmaceutical Sciences(JCPS) Volume 9 Issue 2, April - June 2016 .

[34] Anuradha.C, Khanna.V, "A novel gsm based control for e-devices" Journal of Chemical and Pharmaceutical Sciences(JCPS) Volume 9 Issue 2, April - June 2016 .

[35] Anuradha.C, Khanna.V, "Secured privacy preserving sharing and data integration in mobile web environments " Journal of Chemical and Pharmaceutical Sciences(JCPS) Volume 9 Issue 2, April - June 2016 .

[36] Sundarraj, B., Kaliyamurthie, K.P. Social network analysis for decisive the ultimate classification from the ensemble to boost accuracy rates 2016 International Journal of Pharmacy and Technology 8

[37] Sundarraj, B., Kaliyamurthie, K.P. A content-based spam filtering approach victimisation artificial neural networks 2016 International Journal of Pharmacy and Technology 83.

[38] Sundarraj, B., Kaliyamurthie, K.P. Remote sensing imaging for satellite image segmentation 2016 International Journal of Pharmacy and Technology 83 .

[39] Sivaraman, K., Senthil, M. Intuitive driver proxy control using artificial intelligence 2016 International Journal of Pharmacy and Technology 84.

[40] Sivaraman, K., Kaliyamurthie, K.P. Cloud computing in mobile technology2016 Journal of Chemical and Pharmaceutical Sciences 92.

[41] Sivaraman, K., Khanna, V.Implementation of an extension for browser to detect vulnerable elements on web pages and avoid click jacking 2016 Journal of Chemical and Pharmaceutical Sciences 92. 


\section{Reckoning examination for precip soothsaying}

\section{AUTHORS PROFILE}

D.Jeyapriya, Assistant Professor,

Department of Computer Science \&

Engineering, Bharath Institute of

Higher Education and Research,

Chennai, India

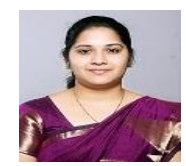

S.Amudha ,Department of CSE,,Bharath Institute of

Higher

Education

Research,Chennai,Thamilnadu,India.

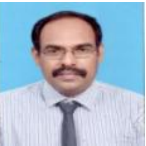

G.Michael, Associate Professor,Department of CSE

Bharath Institute of Higher Education and Research,

Chennai, Tamilnadu, India.

B.Sundarraj, Assistant Professor, Department of Computer Science \& Engineering, Bharath Institute of Higher Education and Research, Chennai, India 